\title{
Risk factors for chronic periodontitis in Sri Lankan adults: a population based case-control study
}

\author{
Nimali Wellapuli ${ }^{1}$ and Lilani Ekanayake ${ }^{2^{*}}$
}

\begin{abstract}
Objective: To determine risk factors for chronic periodontitis in 30-60 year olds in Sri Lanka. Cases and controls for this population based unmatched case-control study were identified from a broader cross-sectional study which was conducted to determine the prevalence of chronic periodontitis in 30-60 year old adults in Colombo district Sri Lanka. The study included 694 cases and 706 controls. Data were collected by means of a pre-tested interviewer administered questionnaire to obtain information about socio-demographic and behavioural factors, a physical examination to record anthropometric measurements and an oral examination.
\end{abstract}

Results: Being a male, a Muslim, belonging to the 45-60 year old age group, having less than 12 years of education, using the finger to clean teeth, current smoking, current betel quid chewing, self-reported diabetes and hypertension emerged as risk factors for chronic periodontitis.

Conclusions: Several socio-demographic and behavioural factors as well as co-morbid conditions emerged as independent risk factors for chronic periodontits in this population. The findings could be used for planning programmes to reduce the burden of chronic periodontits in Colombo district Sri Lanka.

Keywords: Case-control study, Chronic periodontitis, Risk factors, Sri Lanka

\section{Introduction}

Chronic periodontitis is an inflammatory disease that affects $11 \%$ of the global population [1]. Further it has a significant impact on the quality of life of individuals [2]. Studies from many developed countries indicate that several modifiable and non-modifiable risk factors such as socio-economic position, smoking, alcohol, diabetes, obesity, hypertension, stress and genetic factors are associated with the disease $[3,4]$.

As chronic periodontits results from a complex interaction between bacterial infection, host response and risk factors [5], it is possible that population specific characteristics such as ethnicity, genetic, behavioural and environmental factors may operate in different ways in the expression of periodontitis in different populations.

\footnotetext{
*Correspondence: lilanie@pdn.ac.lk

${ }^{2}$ Faculty of Dental Sciences, University of Peradeniya, Peradeniya, Sri Lanka

Full list of author information is available at the end of the article
}

Therefore risk factors for chronic periodontis for populations from developed countries may not necessarily be the same for populations from developing countries.

The prevalence of periodontal disease is high (90\%) in Sri Lanka [6] but information on risk factors for periodontitis is lacking for Sri Lankans. The available information on this topic is limited to the associations between tobacco use, oral hygiene practices and periodontal disease [7]. Therefore there is a need to identify what additional factors are associated with chronic periodontitis in Sri Lankans. The aim of the present study was to determine risk factors for chronic periodontitis in 30-60 year olds in Sri Lanka.

\section{Methods}

Cases and controls for this population based unmatched case-control study were identified from a broader study that was conducted to determine the prevalence of chronic periodontitis in 30-60 year old adults in Colombo district, 
Sri Lanka [8]. The sample of that study included 1400 participants who have been residents of the district for a continued period of 1 year or more. Pregnant women, temporary lodgers and the physically and mentally challenged were excluded.

Case definitions developed by the Centers for Disease Control and Prevention/American Academy of Periodontology (CDC/AAP) were used to define moderate and severe periodontitis [9]. Severe periodontitis was defined as having $\geq 2$ inter-proximal sites with clinical attachment loss (CAL) of $\geq 6 \mathrm{~mm}$ (not on the same tooth) and $\geq 1$ inter-proximal sites with probing depth (PD) of $\geq 5 \mathrm{~mm}$ (not on the same tooth) and moderate periodontitis was defined as $\geq 2$ inter-proximal sites with CAL of $\geq 4 \mathrm{~mm}$ (not on the same tooth) or $\geq 2$ inter-proximal sites with PD of $\geq 5 \mathrm{~mm}$ (not on the same tooth). A participant with either moderate or severe periodontitis was considered as a case.

OpenEpi sample size calculator for unmatched casecontrol studies was used to calculate the sample size [10]. Overweight/obesity is considered as a risk factor for chronic periodontitis [11]. Therefore the prevalence of overweight/obesity (49\%) in 20-60 year olds in Colombo district was considered to calculate the sample size [12]. Assuming that the exposure rate among controls is $49 \%$ and to detect an odds ratio of 2 with a power of $80 \%$, at a significance level of 5\%, a minimum of 137 cases and controls were needed. However based on the CDC/AAP definition, 694 cases with moderate/severe periodontitis and 706 controls were identified from the main study [8]. Therefore to enhance the power of the study, all 694 cases and 706 controls identified from that study were included in the present study. A detailed description of the methodology of the cross-sectional study is described elsewhere [2].

A pre-tested interviewer administered questionnaire was used to obtain information on socio-demographics, behavioural factors and co-morbid conditions. A physical examination was carried out to record anthropometric measurements. The oral examination included the assessment of probing pocket depth (PPD) and clinical attachment loss (CAL) on six surfaces of all teeth (mesiobuccal, buccal, disto-buccal, disto-lingual, lingual and mesio-lingual surfaces) excluding the third molars. All periodontal parameters were recorded using the University of North Carolina (UNC)-12 probe (Hu-Friedy Manufacturing Co, Chicago, USA). Anthropometric measurements included standing body height, weight and waist circumference. Measurements were made when the participant was in upright position, wearing light indoor clothing without footwear or any heavy items in the pockets. Data collection took place at the participant's home. The first author (calibrated against a professor in Periodontology) recorded the periodontal parameters under an artificial head light when the participant was seated on a chair. Two field assistants, one of whom was conversant in both the Sinhala and Tamil languages administered the questionnaire to the participants. Anthropometric measurements were recorded by a trained field assistant. In order to determine intraexaminer variability of periodontal parameters $5 \%$ of the sample was re-examined. Kappa statistics of PPD and CAL measurements were 0.87 and 0.92 respectively.

Data were analysed using SPSS 20.0 software (SPSS Inc, Chicago, Il, USA). Body mass index (BMI) cut-offs were defined based on the proposed WHO categories for Asians: underweight $(<18.5)$, normal weight $(18.5-23.0)$, overweight $(>23.0$ to $<27.5)$ and obese $(\geq 27.5)$ [13]. Smoking status was defined as; never if never smoked during life time; former if had discontinued for more than 1 year before data collection and current if smoked either daily or on some days at the time of data collection. Lifetime exposure to smoking was determined in terms of pack-years (number smoked per day/20 $\times$ number of years of smoking) for both former and current smokers. Chi square test was used to determine the differences in categorical exposure variables in cases and controls while Mann-Whitney test was used to assess the difference in pack-years smoked. Multiple backward stepwise conditional logistic regression analysis was used to determine the independent effects of exposure variables on chronic periodontitis. A level of $\mathrm{p}<0.05$ significance was considered as the cut-off to retain an exposure variable in the adjusted model. Only those variables that were associated with chronic periodontitis at $p<0.05$ level in the unadjusted logistic regression models were included in the final model. Smoking in pack-years was included as a continuous variable. Interactions between alcohol $\times$ smoking, smoking $\times$ alcohol $\times$ betel chewing on chronic periodontitis were also assessed.

\section{Results}

The mean age of cases and controls were 47.1 (SD 9.5) and 40.1 (SD 9.1) years respectively. Sixty two percent of the cases and $41 \%$ of the controls were males.

Cases and controls differed significantly in relation to sex, age group, ethnicity, level of education and current occupation category (Table 1).

Except tooth brushing frequency, all behavioural variables considered differed significantly between cases and controls. Self-reported diabetes and self-reported hypertension were significantly higher in cases than in controls (Table 2).

Accordingly to the multiple backward stepwise logistic regression analysis being a male, a Muslim, belonging to the $45-60$ year old age group, having $0-5,6-10$, and 
Table 1 Comparison socio-demographic exposure variables between cases and controls

\begin{tabular}{|c|c|c|c|c|c|}
\hline \multirow[t]{2}{*}{ Variable } & \multicolumn{2}{|c|}{ Cases (694) } & \multicolumn{2}{|c|}{ Controls (706) } & \multirow[t]{2}{*}{ p value } \\
\hline & $\mathrm{n}$ & $\%$ & $\mathrm{n}$ & $\%$ & \\
\hline \multicolumn{6}{|l|}{ Sex } \\
\hline Female & 261 & 37.6 & 419 & 59.3 & \multirow[t]{2}{*}{$<0.001$} \\
\hline Male & 433 & 62.4 & 287 & 40.7 & \\
\hline \multicolumn{6}{|l|}{ Age group (years) } \\
\hline $30-44$ & 298 & 42.9 & 374 & 53.0 & \multirow[t]{2}{*}{$<0.001$} \\
\hline $45-60$ & 396 & 57.1 & 332 & 47.0 & \\
\hline \multicolumn{6}{|l|}{ Ethnicity } \\
\hline Sinhala & 545 & 82.4 & 581 & 79.2 & \multirow[t]{3}{*}{0.033} \\
\hline Tamil & 75 & 11.5 & 81 & 10.9 & \\
\hline Muslim & 68 & 6.1 & 43 & 9.9 & \\
\hline \multicolumn{6}{|c|}{ Level of education (years) } \\
\hline $0-5$ & 86 & 12.4 & 50 & 7.1 & \multirow[t]{4}{*}{$<0.001$} \\
\hline $6-10$ & 277 & 39.9 & 197 & 27.9 & \\
\hline $11-12$ & 299 & 43.1 & 401 & 56.8 & \\
\hline$>12$ & 32 & 4.6 & 58 & 8.2 & \\
\hline \multicolumn{6}{|c|}{ Monthly household income (Rupees) } \\
\hline$\leq 20,000$ & 494 & 71.2 & 512 & 72.5 & \multirow[t]{2}{*}{0.57} \\
\hline$>20,000$ & 200 & 28.8 & 194 & 27.5 & \\
\hline \multicolumn{6}{|c|}{ Current occupation $^{\mathrm{a}}$} \\
\hline Low category & 568 & 81.8 & 526 & 74.5 & \multirow[t]{2}{*}{0.001} \\
\hline High category & 126 & 18.2 & 180 & 25.5 & \\
\hline
\end{tabular}

For all variables but ethnicity, the total number of cases and controls were 694 and 706 respectively. With regards to ethnicity, seven participants who belonged to minor races were excluded in the analysis; cases $=688$ and control $=705$ )

${ }^{a}$ Low $=$ unskilled/skilled larbourer, unemployed for males, housewife, lower business; high $=$ professional, managerial, clerical, technical, upper business

11-12 years of education compared to $>12$ years of education, using the finger to clean teeth, current smoking, current betel quid chewing, self-reported diabetes and self-reported hypertension were independently associated with chronic periodontitis. None of the interactions considered was significant in the final model (Table 3).

\section{Discussion}

This study is the first to identify a range of risk factors for chronic periodontitis in a large sample of Sri Lankan adults using CDC/AAP case definitions.

Age was the strongest socio-demographic risk factor for chronic periodontitis, a finding consistent with other studies [7, 14]. It is well established that ageing per se does not increase the susceptibility to chronic periodontitis but greater periodontal destruction observed with increasing age is due to the cumulative effect of previous disease activity [15]. However age-dependent alterations in innate immunity and inflammatory status could increase the susceptibility to periodontitis [16]. Chronic periodontitis is more prevalent in men than in women
Table 2 Comparison of behavioural exposure variables and co-morbid conditions between cases and controls

\begin{tabular}{|c|c|c|c|c|c|}
\hline \multirow[t]{2}{*}{ Variable } & \multicolumn{2}{|c|}{ Cases (694) } & \multicolumn{2}{|c|}{$\begin{array}{l}\text { Controls } \\
\text { (706) }\end{array}$} & \multirow[t]{2}{*}{$p$ value } \\
\hline & $\mathbf{n}$ & $\%$ & $\mathrm{n}$ & $\%$ & \\
\hline \multicolumn{6}{|l|}{ Mode of tooth cleaning } \\
\hline Brush & 673 & 97.0 & 703 & 99.6 & $<0.001$ \\
\hline Finger & 21 & 3.0 & 3 & 0.4 & \\
\hline \multicolumn{6}{|l|}{ Material used for tooth cleaning } \\
\hline Toothpaste & 666 & 96.0 & 698 & 98.9 & 0.001 \\
\hline Other & 28 & 4.0 & 8 & 1.1 & \\
\hline \multicolumn{6}{|l|}{ Tooth cleaning frequency } \\
\hline Once/day & 125 & 18.0 & 105 & 14.9 & 0.11 \\
\hline >Once/day & 569 & 82.0 & 601 & 85.1 & \\
\hline \multicolumn{6}{|l|}{ Smoking } \\
\hline Never & 432 & 62.2 & 603 & 85.4 & $<0.001$ \\
\hline Former & 80 & 11.5 & 45 & 6.4 & \\
\hline Current & 182 & 26.2 & 58 & 8.2 & \\
\hline $\begin{array}{l}\text { Lifetime exposure to smoking in } \\
\text { pack-years }^{\mathrm{a}}\end{array}$ & 0 & $(0-45)$ & 0 & $(0-79.2)$ & $<0.001$ \\
\hline \multicolumn{6}{|l|}{ Betel quid chewing } \\
\hline No & 583 & 84.0 & 666 & 94.3 & $<0.001$ \\
\hline Current chewer & 111 & 16.0 & 40 & 5.7 & \\
\hline \multicolumn{6}{|l|}{ Alcohol consumption } \\
\hline Never & 299 & 43.1 & 442 & 62.6 & $<0.001$ \\
\hline Ever & 395 & 56.9 & 264 & 37.4 & \\
\hline \multicolumn{6}{|l|}{ Self-reported diabetes } \\
\hline No & 590 & 85.0 & 658 & 93.2 & $<0.001$ \\
\hline Yes & 104 & 15.0 & 48 & 6.8 & \\
\hline \multicolumn{6}{|l|}{ Self-reported hypertension } \\
\hline No & 562 & 81.0 & 647 & 91.6 & $<0.001$ \\
\hline Yes & 132 & 19.0 & 59 & 8.4 & \\
\hline \multicolumn{6}{|l|}{ Overweight/obese ${ }^{b}$} \\
\hline No & 292 & 42.1 & 266 & 37.7 & 0.09 \\
\hline Yes & 402 & 57.9 & 440 & 62.3 & \\
\hline \multicolumn{6}{|l|}{ Abdominal obesity ${ }^{c}$} \\
\hline Normal & 318 & 45.8 & 325 & 46.0 & 0.93 \\
\hline With abdominal obesity & 376 & 54.2 & 381 & 54.0 & \\
\hline
\end{tabular}

a Median, (minimum and maximum) values given

b Overweight/obese based on BMI $>23.0$ cut-off for Asian populations

c Abdominal obesity based on waist circumference $\geq 80 \mathrm{~cm}$ and $\geq 90 \mathrm{~cm}$ for adult females and males respectively for Asian populations

$[17,18]$ and the sex difference has been attributed to life styles differences [3]. But sex emerged as an independent risk factor following adjustment for confounding effects of life style factors such as tooth cleaning habits, smoking and betel quid chewing. Sex differences in periodontal disease may also be due to gender-based heterogeneity in immune responses [19]. Being a Muslim was a risk factor for chronic periodontitis and the first study 
Table 3 Factors associated with chronic periodontitis (backward stepwise multiple logistic regression analysis)

\begin{tabular}{|c|c|c|c|c|c|c|}
\hline \multirow[t]{2}{*}{ Variable } & \multicolumn{2}{|c|}{ Unadjusted } & \multirow[t]{2}{*}{$p$ value } & \multicolumn{2}{|c|}{ Adjusted } & \multirow[t]{2}{*}{$\mathrm{p}$ value } \\
\hline & OR & $95 \% \mathrm{Cl}$ & & OR & $95 \% \mathrm{Cl}$ & \\
\hline \multicolumn{7}{|l|}{ Sex } \\
\hline Female & 1.00 & & & 1.00 & & \\
\hline Male & 2.42 & $1.95-3.00$ & $<0.001$ & 1.97 & $1.47-2.65$ & $<0.001$ \\
\hline \multicolumn{7}{|l|}{ Age group (years) } \\
\hline $30-44$ & 1.00 & & & 1.00 & & \\
\hline $45-60$ & 4.29 & $3.41-5.40$ & $<0.001$ & 4.19 & $3.23-5.44$ & $<0.001$ \\
\hline \multicolumn{7}{|l|}{ Ethnicity } \\
\hline Sinhala & 1.00 & & & 1.00 & & \\
\hline Tamil & 0.99 & $0.71-1.38$ & 0.94 & 0.77 & $0.51-1.14$ & 0.19 \\
\hline Muslim & 1.69 & $1.31-2.51$ & 0.01 & 1.63 & $1.03-2.58$ & 0.04 \\
\hline \multicolumn{7}{|l|}{ Level of education (years) } \\
\hline$>12$ & 1.00 & & & 1.00 & & \\
\hline $11-12$ & 1.35 & $0.86-2.13$ & 0.20 & 1.68 & $1.00-2.83$ & 0.05 \\
\hline $6-10$ & 2.55 & $1.60-4.07$ & $<0.001$ & 2.80 & $1.63-4.81$ & $<0.001$ \\
\hline $0-5$ & 3.12 & $1.79-5.43$ & $<0.001$ & 2.39 & $1.23-4.61$ & 0.01 \\
\hline \multicolumn{7}{|l|}{ Monthly household income (Rupees) } \\
\hline$\leq 20,000$ & 1.00 & & & & & \\
\hline$>20,000$ & 1.07 & $0.85-1.35$ & 0.58 & & & \\
\hline \multicolumn{7}{|l|}{ Current occupation } \\
\hline Low category & 1.00 & & & & & \\
\hline High category & 0.65 & $0.50-0.84$ & 0.001 & & & \\
\hline \multicolumn{7}{|l|}{ Mode of tooth cleaning } \\
\hline Brush & 1.00 & & & 1.00 & & \\
\hline Finger & 7.31 & $2.17-24.63$ & 0.001 & 4.30 & $1.05-17.61$ & 0.04 \\
\hline \multicolumn{7}{|l|}{ Material used for tooth cleaning } \\
\hline Toothpaste & 1.00 & & & & & \\
\hline Others & 3.67 & $1.66-8.11$ & 0.001 & & & \\
\hline \multicolumn{7}{|l|}{ Tooth cleaning frequency } \\
\hline Once/day & 1.00 & & & & & \\
\hline >once/day & 0.80 & $0.60-1.06$ & 0.11 & & & \\
\hline \multicolumn{7}{|l|}{ Smoking } \\
\hline Never & 1.00 & & & 1.00 & & \\
\hline Former & 2.48 & $1.69-3.65$ & $<0.001$ & 1.21 & $0.76-1.93$ & 0.43 \\
\hline Current & 4.38 & $3.18-6.03$ & $<0.001$ & 3.27 & $2.21-4.85$ & $<0.001$ \\
\hline Smoking in pack-years & 1.15 & $1.10-1.20$ & $<0.001$ & & & \\
\hline \multicolumn{7}{|l|}{ Betel quid chewing } \\
\hline No & 1.00 & & & 1.00 & & \\
\hline Current chewer & 3.17 & $2.17-4.63$ & $<0.001$ & 2.05 & $1.34-3.14$ & 0.001 \\
\hline \multicolumn{7}{|l|}{ Alcohol use } \\
\hline Never & 1.00 & & & & & \\
\hline Ever & 2.21 & $1.79-2.74$ & $<0.001$ & & & \\
\hline \multicolumn{7}{|l|}{ Alcohol $\times$ smoking } \\
\hline Never/never & 1.00 & & & & & \\
\hline Ever/former smoker & 2.37 & $1.61-3.50$ & $<0.001$ & & & \\
\hline Ever/current smoker & 4.02 & $2.89-5.60$ & $<0.001$ & & & \\
\hline \multicolumn{7}{|l|}{ Alcohol $\times$ betel chewing $\times$ smoking } \\
\hline Never/never/never & 1.00 & & & & & \\
\hline Ever alcohol user $\times$ current chewer $\times$ former smoker & 3.43 & $1.36-8.64$ & 0.009 & & & \\
\hline
\end{tabular}


Table 3 continued

\begin{tabular}{|c|c|c|c|c|c|c|}
\hline \multirow[t]{2}{*}{ Variable } & \multicolumn{2}{|c|}{ Unadjusted } & \multirow[t]{2}{*}{$p$ value } & \multicolumn{2}{|c|}{ Adjusted } & \multirow[t]{2}{*}{$\mathrm{p}$ value } \\
\hline & OR & $95 \% \mathrm{Cl}$ & & OR & $95 \% \mathrm{Cl}$ & \\
\hline Ever alcohol user $\times$ current chewer $\times$ current smoker & 4.45 & $2.13-9.30$ & $<0.001$ & & & \\
\hline \multicolumn{7}{|l|}{ Self-reported diabetes } \\
\hline No & 1.00 & & & 1.00 & & \\
\hline Yes & 2.15 & $1.69-3.46$ & $<0.001$ & 1.55 & $1.01-2.36$ & 0.04 \\
\hline \multicolumn{7}{|l|}{ Self-reported hypertension } \\
\hline No & 1.00 & & & 1.00 & & \\
\hline Yes & 2.58 & $1.86-3.57$ & $<0.001$ & 1.77 & $1.20-2.60$ & 0.004 \\
\hline \multicolumn{7}{|l|}{ Overweight/obese } \\
\hline No & 1.00 & & & & & \\
\hline Yes & 0.83 & $0.67-1.03$ & 0.09 & & & \\
\hline \multicolumn{7}{|l|}{ Abdominal obesity } \\
\hline No & 1.00 & & & & & \\
\hline Yes & 1.01 & $0.82-1.25$ & 0.94 & & & \\
\hline
\end{tabular}

to show an association between ethnicity and chronic periodontitis among Sri Lankans. The link between race/ ethnicity and periodontitis may be due an indirect effect through mediators such as education, income and occupation rather than to confounders [20]. Socio-economic position whether assessed in terms of education, occupation or income is a predictor of chronic periodontitis but education is more important than income or occupation [21]. Only low educational attainment emerged as a risk factor for chronic periodontitis indicating that different socio-economic indicators contribute differently to chronic periodontitis in different populations.

Those using the finger to clean their teeth were more likely to be at risk of chronic periodontitis than those who used the toothbrush. Use of finger will not remove dental plaque which is the main aetiological agent for chronic periodontitis. A similar finding has been reported previously [7].

Consistent with previous studies [22], current smoking emerged as a strong risk factor for chronic periodontitis but former smoking was not. Smoke cessation has a positive influence on the occurrence of periodontitis [23]. However according to some studies both current and former smokers are at a higher risk of chronic periodontitis than non-smokers [24]. A dose-response association between smoking and periodontitis has been observed [7, 24] but the number of pack-years of smoking was not associated with chronic periodontitis in the present study. There are two possible reasons for this finding. First, current levels of smoking may not necessarily reflect past exposure in all individuals. Second, the number of pack-years of smoking may overestimate lifetime exposure for current smokers who are not daily users. Betel quid chewing; a mixture of areca, slaked lime and tobacco wrapped in betel leaf is a common practice in South Asia. But the effect of this habit on chronic periodontitis has received limited attention. Consistent with the findings of Akhter et al. [25], betel quid chewing was associated with chronic periodontitis. However, Amarasena et al. [7] found that betel chewing was not associated with periodontitis in Sri Lankans. In addition to betel leaf, chewers use ingredients such as areca, lime and tobacco in the quid. It is possible that these ingredients may also have deleterious effects on the periodontium. Therefore further studies on the effects of these additives on periodontal health are warranted. Alcohol use was not associated with chronic periodontitis. In contrast a recent meta-analysis suggests that alcohol consumption is associated with an increased risk of periodontitis [26].

The effects of three co-morbid conditions were also assessed. Overweight/obesity and abdominal obesity were not associated with periodontitis. But systematic reviews suggest that overweight, obesity and increased waist circumference may be risk factors for development of periodontitis [11]. Consistent with other reports [27], self- reported diabetes emerged as a risk factor for chronic periodontitis. The relationship between diabetes and periodontal disease is considered to be bi-directional; hyperglycemia in diabetics can lead to increased inflammation thus contributing to increased periodontal destruction [28] and periodontal infection could adversely affect glycemic control in diabetics [29]. Selfreported hypertension was associated with chronic periodontitis and in agreement with previous studies [30]. Changes in microcirculation associated with hypertension may cause ischaemia in the periodontium favouring the development of periodontal disease [31]. 


\section{Conclusion}

Several socio-demographic and behavioural factors as well as co-morbid conditions emerged as independent risk factors for chronic periodontits in this population. The findings of this study could be used for identifying high risk individuals, patient education and planning programmes to reduce the burden of chronic periodontits in Colombo district Sri Lanka.

\section{Limitations}

This study has some limitations. The prevalence of diabetes and hypertension may have been under-estimated as they were based on self-reports. However detecting previously undiagnosed cases were beyond the scope of this study. It is possible that participants may have under-reported unhealthy habits such as smoking and alcohol use leading to information bias. Although steps were taken to minimize this bias to the best possible extent, it may not have been eliminated completely. As the study was confined to adults in Colombo district it may not be possible to directly generalize the findings to the wider Sri Lankan adult population.

\section{Abbreviations \\ CDC/AAP: Centers for Disease Control and Prevention/American Academy of Periodontology; CAL: clinical attachment loss; PPD: probing pocket depth; BMl: body mass index.}

\section{Authors' contributions}

NW and LE conceived the design of the study. NW collected the data, analysed the data and wrote the first draft of the manuscript. LE was involved in the supervision of the study and critically reviewed the manuscript for important intellectual content. Both authors read and approved the final manuscript.

\section{Author details}

${ }^{1}$ Ministry of Health, Nutrition and Indigenous Medicine, Colombo, Sri Lanka.

${ }^{2}$ Faculty of Dental Sciences, University of Peradeniya, Peradeniya, Sri Lanka.

\section{Acknowledgements}

None.

\section{Competing interests}

The authors declare that there are no competing interests.

\section{Availability of data and materials}

The data set generated or analysed during the current study are available from the first author-Dr. Nimali Wellapuli on reasonable request.

\section{Consent for publication}

Not applicable.

\section{Ethical approval and consent to participate}

Ethical Review Committee of the Faculty of Medical Sciences, University of Sri Jayewardenepura, Sri Lanka granted ethical clearance for this study. Application no: 608/12. Also written informed consent was obtained from all participants.

\section{Funding}

None.

\section{Publisher's Note}

Springer Nature remains neutral with regard to jurisdictional claims in published maps and institutional affiliations.
Received: 14 July 2017 Accepted: 31 August 2017

Published online: 07 September 2017

\section{References}

1. Marcenes W, Kassebaum NJ, Bernabé E, Flaxman A, Naghavi M, Lopez A, Murray CJ. Global burden of oral conditions in 1990-2010: a systematic analysis. J Dent Res. 2013:92:592-7.

2. Wellapuli N, Ekanayake L. Association between chronic periodontitis and oral health-related quality of life in Sri Lankan adults. Int Dent J. 2016;66:337-43.

3. Genco RJ, Borgnakke WS. Risk factors for periodontal disease. Periodontology. 2000;2013:59-94.

4. Van Dyke TE, Dave S. Risk factors for periodontitis. J Int Acad Periodontal. 2005;7:3-7.

5. American Academy of Periodontology. The pathogenesis of periodontal diseases. J Periodontol. 1999;70:457-70.

6. Ministry of Healthcare and Nutrition. National oral health survey 2002-2003. Colombo: Ministry of Healthcare and Nutrition; 2009.

7. Amarasena N, Ekanayake AN, Herath L, Miyazaki H. Tobacco use and oral hygiene as risk indicators for periodontitis. Community Dent Oral Epidemiol. 2002;30:115-23

8. Wellapuli N. Chronic periodontitis among 30-60 year olds in Colombo district. MD thesis, Colombo: Post Graduate Institute of Medicine; 2014.

9. Page RC, Eke PL. Case definitions for use in population-based surveillance of periodontitis. J Periodontol. 2007:8:1387-99.

10. OpenEpi-sample size for unmatched case-control studies. http://www. openepi.com/SampleSize/SCCC.htm. Accessed 23 Mar 2012.

11. Keller A, Rohde JF, Raymond K, Heitmann BL. Association between periodontal disease and overweight and obesity: a systematic review. J Periodontol. 2015:86:766-76.

12. Aramepola C. Abdominal obesity and its association with selected risk factors of coronary heart disease in adult population in the district of Colombo. Doctor of Medicine thesis, Colombo: Post Graduate Institute of Medicine; 2004

13. World Health Organization. Appropriate body-mass index for Asian populations and its implication for policy and intervention strategies. Lancet. 2004;363:157-63.

14. Haas AN, Wagner MC, Oppermann RV, Rösing CK, Albandar JM, Susin C. Risk factors for the progression of periodontal attachment loss: a 5-year population- based study in South Brazil. J Clin Periodontol. 2014:41:215-23.

15. Dye BE. Global epidemiology of periodontal disease. Periodontology. 2000:2012(58):10-25.

16. Hajishengallis $G$. Aging and its impact on innate immunity and inflammation: implications for periodontitis. J Oral Biosci. 2014:56:30-7.

17. Zhang Q, Li Z, Wang C, et al. Prevalence and predictors of periodontitis among adults in China, 2010. Glob Health Action. 2015;7:24503.

18. Eke PI, Dye BA, Wei L, Slade GD, Thornton-Evans GO, Borgnakke WS, Taylor GW, Page GS, Beck JD, Genco RJ. Update of prevalence of periodontitis in adults in the United States: NHANES 2009-2012. J Periodontol. 2015;86:611-22.

19. Grover V, Jain A, Kapoor A, Malhotra R, Chahal GS. The gender bender effect in periodontal immune response. Endocr Metab Disord Drug Targets. 2016;16:12-20.

20. Borrell LN, Crawford ND. Socioeconomic position indicators and periodontitis: examining the evidence. Periodontology. 2000;2012:69-83.

21. Sim SJ, Han DH. Association between childhood socioeconomic position and periodontitis in Korean adults. Community Dent Health. 2015;32:153-7.

22. Jang A-Y, Lee J-K, Shin J-Y, Lee H-Y. Association between smoking and periodontal disease in Korean adults: the fifth Korea National Health and Nutrition Examination survey (2010-2012). Korean J Fam Med. 2016;37:117-22.

23. Fiorini T, Musskopf ML, Oppermann RV, Susin C. Is there a positive effect of smoking cessation on periodontal health? A systematic review. J Periodontal. 2014:85:83-91. 
24. Moimaz SA, Zina LG, Saliba O, Garbin CA. Smoking and periodontal disease: clinical evidence for an association. Oral Health Prev Dent. 2009;7:369-76.

25. Akhter R, Hassan NM, Aida J. Relationship between betel quid addictives and established periodontitis among Bangladeshi subjects. J Clin Periodontol. 2008;35:9-15.

26. Wang J, LV J, Wang W, Jiang X. Alcohol consumption and risk of periodontitis: a meta analysis. J Clinl Periodontol. 2016;43:572-83.

27. Chávarry NG, Vettore MV, Sansone C, Sheiham A. The relationship between diabetes mellitus and destructive periodontal disease; a meta analysis. Oral Health Prev Dent. 2009;7:107-27.
28. Brownlee M. The pathobiology of diabetic complications: a unifying mechanism. Diabetes. 2005;54:1615-25.

29. Chapple IL, Genco R. Diabetes and periodontal disease: consensus report of the Joint EFP/AAP workshop on periodontitis and systemic diseases. J Clin Periodontol. 2013;84(Suppl 4):S106-12.

30. Vidal F, Figueredo CM, Cordovil I, Fischer RG. Higher prevalence of periodontitis in patients with refractory arterial hypertension: a case-control study. Oral Dis. 2011;17:560-3.

31. Macedo Paizan ML, Vilele-Martin JF. Is there an association between periodontits and hypertension? Curr Cardiol Rev. 2014;10:355-61.

\section{Submit your next manuscript to BioMed Central and we will help you at every step:}

- We accept pre-submission inquiries

- Our selector tool helps you to find the most relevant journal

- We provide round the clock customer support

- Convenient online submission

- Thorough peer review

- Inclusion in PubMed and all major indexing services

- Maximum visibility for your research

Submit your manuscript at www.biomedcentral com/submit 